although only around $10 \%$ of the total naphthalene present is converted at higher protein concentrations, an appreciable fraction of the very small amount of hydrocarbon added may rapidly dissolve into microsomal structures rich in lipids where it is not immediately accessible to oxidation during the limited time period during which the reaction was followed. By adding $15-20 \mu \mathrm{l}$ of a $4 \times 10^{-2} \mathrm{M}$ unlabelled naphthalene solution in ethanol the range of linearity was extended as shown in Fig. 2. A more detailed analysis of the microsomal oxidation of hydrocarbons will be published elsewhere. ${ }^{5}$ The Fenton reagent as expected, ${ }^{\circ}$ efficiently oxidized naphthalene.

Acknowledgements. The authors wish to express their gratitude to Dr. Gustaf Dallner for fruitful discussions and for kindly supplying us with rat liver microsomes. This work has been supported by grants from the Knut and Alice Wallenberg Foundation.

1. Ahnström, G. and Rosén, C.-G. Acta Chem. Scand. 19 (1965) 263.

2. Corner, E. D. S. and Young, L. Biochem. J. 58 (1954) 647.

3. Mitoma, C., Posner, H. S., Reitz, H. C. and Udenfriend, S. Arch. Biochem. Biophys. 61 (1956) 431.

4. Booth, J. and Boyland, E. Biochem. J. 66 (1957) 73 .

5. Nilsson, R. To be published.

6. Ahnström, G. et al. To be published.

7. Ernster, L., Siekevitz, P. and Palade, G. E. J. Cell. Biol. 15 (1962) 541.

8. Hullán, L., Sontagh, T., Turtóczky, I. and Fedorcsák, I. Acta Chem. Scand. 19 (1965) 2440.

9. Baxendale, J. H. and Magee, J. Discussions Faraday Soc. 14 (1953) 160.

Received April 28, 1967.

\section{The Molecular Structure of Oxalyl Chloride. An Electron Diffraction Study}

\section{K. E. HJORTAAS}

Kjemisk institutt, Norges laererhфgskole,
Trondheim, Norway

Several investigations have been performed on the molecular structure of oxalyl chloride, $\mathrm{C}_{2} \mathrm{O}_{2} \mathrm{Cl}_{2}$. Luvalle ${ }^{1}$ obtained from electron diffraction data the bond distances and angles listed in Table 1. Groth and Hassel suggested that the molecule in the solid phase is nearly in the planar trans form. ${ }^{2}$ The X-ray diffraction method had been used. Contrary to what had been reported earlier, ${ }^{3}$ Hencher and King claimed that a satisfactory analysis of the infrared and Raman spectra of oxalyl chloride can be made by assuming the molecules to be in the planar trans form only." A dipole moment for oxalyl chloride in the benzene solution has been reported..$^{5}$ However, microwave investigations on oxalyl chloride in the gas phase did not indicate any dipole moment. Because of the conflicting opinions which are found in the literature as to the structure of oxalyl chloride, it was decided to make further investigations by the electron diffraction method.

Experimental. The electron diffraction data were obtained at the University of Oslo. The nozzle-to-plate distances were about 48 and 19 (cm). A modified $s^{3}$ sector was used. The data were treated according to the procedure described by Almenningen et al. ${ }^{7}$ An experimental background was first drawn and later on

Table 1. Least-squares results. Distances $r_{g}(1)^{8}$ and root-mean-squares amplitudes of vibration $(u)$ both with standard deviations $(\sigma)$ in $\AA$. Uncertainty of wavelength is also included in $\sigma_{r}$.

$\begin{array}{llrrr} & r_{g}(1) & \sigma_{r} & u & \sigma_{u} \\ \text { C-C } & 1.534\left(1.50^{1}\right) & 0.003 & 0.033 & 0.003 \\ \text { C-O } & 1.189\left(1.20 \text { ass. }^{1}\right) & 0.002 & 0.045 & 0.001 \\ \text { C-Cl } & 1.749\left(1.72^{1}\right) & 0.003 & 0.058 & 0.001 \\ \text { C-O } & 2.410 & 0.005 & 0.058 & 0.003 \\ \text { O-Cl } & 2.602 & 0.004 & 0.061 & 0.002 \\ \text { C-Cl } & 2.732 & & 0.070 & 0.004\end{array}$

$\angle C C O: 124.1^{\circ}\left(123^{\circ}\right), \angle C l C O: 123.5^{\circ}\left(123^{\circ}\right)$. 
adjusted by considering the observed and the calculated radial distribution (RD) curve for Ångström values less than 1. The experimental molecular intensity function $(s \cdot M(s))$ was obtained for $s$ values from 1.25 to $42.25\left(\AA^{-1}\right)$. The RD curves were obtained by Fourier transformations of the modified intensity functions $8 \cdot M(s) \cdot \exp \left(-0.0009 s^{2}\right)$. The structure was refined by the least-squares methods on the intensity functions treating separately the distances which are depending on the angle of internal oscillation about the $\mathbf{C}-\mathbf{C}$ bond. For these distances the weight functions were chosen proportional to $\exp \left[-4.0 \sin ^{2}(v / 2)\right]$. The angle of internal rotation $v$ is equal to zero for the planar trans form and calculations were done for $v=0,5 \ldots 180 \quad\left({ }^{\circ}\right)$. Complex scattering amplitudes were used.

Structure determination. Each $\mathrm{COCl}$ group and adjacent carbon atom are assumed to be coplanar. Approximate values for the bond distances and bond angles were obtained from the experimental RD function. Some double bond character of the $\mathrm{C}-\mathrm{C}$ bond might be expected if delocalisation of the $\pi$ electrons of the carbonyl groups are assumed. Accordingly, planar molecular models were first considered. On the experimental RD curve there is no peak which might be assigned to the $\mathrm{Cl}-\mathrm{Cl}$ distance for the model in the cis form. The calculated RD curve based on the trans form of the molecular model agreed quite well with the observed one, apart from the outer regions of these curves. Better agreement for this region was obtained when internal oscillation about the $\mathrm{C}-\mathrm{C}$ bond was assumed. The weight functions of the distances $\mathrm{O}-\mathrm{O}, \mathrm{O}-\mathrm{Cl}$, and $\mathrm{Cl}-\mathrm{Cl}$ which are depending on the angle of oscillation, were chosen proportional to $\exp \left[-4.0 \sin ^{2}(v / 2)\right]$, after having tried various functions. The $u$ values of these bonds were assumed independent of the angle of rotation and were chosen equal to $0.070 \AA(\mathrm{O}-\mathrm{O}), 0.090 \AA(\mathrm{O}-\mathrm{Cl})$, and $0.080 \AA(\mathrm{Cl}-\mathrm{Cl})$. The attempt of improving these $u$ values in the least-squares refinement was unsuccessful. This has not yet been studied further. The structural parameters obtained from the least-squares calculations are listed in Table 1. The calculated curves (Figs. 1 and 2) are based on these values. For comparison, the RD curves based on the models in the trans and in the cis form are also drawn in Fig. 2.

Discussion. From this investigation on oxalyl chloride in the gas phase it may be concluded that the planar trans form is the equilibrium conformation but that the

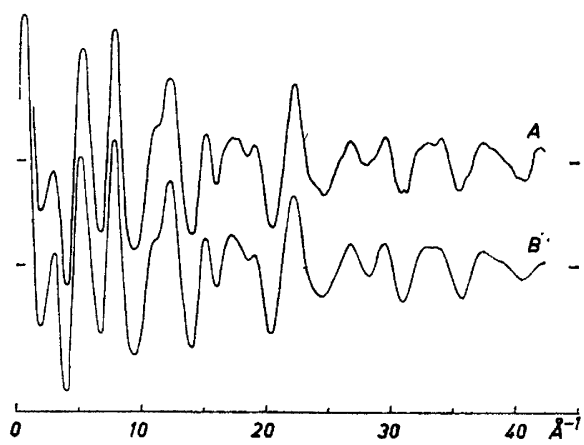

Fig. 1. Experimental (A) and theoretical (B) molecular intensity curves.

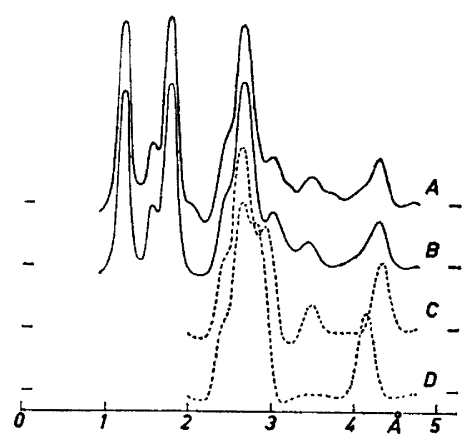

Fig. 2. Radial distribution curves, A, experimental curve and $B$ through $D$ theoretical curves. B, final model, $C$, model in the planar trans form, and D, model in the planar cis form. Artificial damping constant: $k=0.0009 \AA^{2}$.

torsional oscillation about the $\mathrm{C}-\mathrm{C}$ bond has rather large amplitudes. The $\mathrm{C}-\mathrm{C}$ distance obtained (1.534 $\AA$ ) does not indicate any double bond character of this bond.

A full account of this investigation including also diffraction data obtained with $130 \mathrm{~cm}$ between nozzle and plate, will be published later.

The author wishes to thank lic.techn. Marit Trætteberg and siv.ing. Hans M. Seip for valuable discussions and for using their com. puting programs. Thanks are also due to cand.real. Arne Almenningen for making the electron diffraction diagrams, to Mrs. Randi Rian for technical assistance and to Norges almenvitenskapelige forskningsråd for financial support. 
1. Allen, P. W. and Sutton, L. E. Acta Cryst. 3 (1950) 46.

2. Groth, P. and Hassel, O. Acta Chem. Scand. 16 (1962) 2311.

3. Saksena, B. D. and Kagarise, R. E. J. Chem. Phys. 19 (1951) 987.

4. Hecher, J. L. and King, G. W. J. Mol. Spectry. 16 (1965) 158.

5. Martin, G. T. O. and Partington, J. R. J. Chem. Soc. 19361178.

6. Bjorvatten, T. Unpublished results.

7. Almenningen, A., Bastiansen, O., Haaland, A. and Seip, H. M. Angew. Chem. 77 (1965) 877.

8. Bartell, L. S. J. Chem. Phys. 23 (1955) 1219.

Received March 20, 1967.

\section{The Molecular Structure of Silicon Tetraisocyanate}

\section{K. E. HJORTAAS}

\section{Kjemisk institutt, Norges Laererh $\phi g s k o l e$ Trondheim, Norway}

\begin{abstract}
Tnfrared and Raman spectra of silicon tetraisocyanate $\left(\mathrm{Si}(\mathrm{NCO})_{4}\right)$ have been interpreted both by assuming pseudo $T_{d}$ symmetry (not necessarily linear SiNCO group) 1 and by assuming "true" $T_{d}$ symmetry (linear SiNCO group) ${ }^{2}$ for the molecular structure. As electron diffraction and other studies on molecules containing isocyanate groups give the bond angle at the nitrogen atoms different from $180^{\circ}$ (Table 1), it was of interest to investigate $\mathrm{Si}(\mathrm{NCO})$ also by electron diffraction.
\end{abstract}

Experimental. The compound was prepared using the method of Forbes and Anderson. The electron diffraction data were obtained at the University of Oslo. The nozzle-to-plate distances were about 19 and $48(\mathrm{~cm})$. A modified $s^{3}$ sector was used. The data were treated according to the procedure described by Almenningen et al." The experimental background was adjusted by considering the observed and the calculated radial distribution (RD) curve for Ångström values less than 1. The experimental molecular intensity function $(s \cdot M(s))$ was obtained for $s$ values from 1.5 to $45.0\left(\AA^{-1}\right)$. The RD curves were obtained by
Fourier transformations of the modified intensity functions $8 \cdot M(s) \cdot \exp \left(-0.0036 s^{2}\right)$. The structure was refined by the least-squares methods on the intensity functions assuming the $\mathrm{N}-\mathrm{O}$ distance of the NCO group to be "independent" and treating separately the distances depending on the angle of rotation of the NCO groups about the $\mathrm{Si}-\mathrm{N}$ bonds. These distances were calculated for every $30^{\circ}$ of angle of rotation. Complex scattering amplitudes were used.

Structure determination. The molecular models considered were based on the assumption of linear NCO groups and tetrahedral arrangement of the nitrogen atoms. Approximate values of the interatomic distances were obtained from the experimental RD curve which gave only the $\mathrm{Si}-\mathrm{N}$ distance resolved. Various structures were tried and satisfactory agreement was obtained when assuming the $\mathrm{N}-\mathrm{C}$ bond distance somewhat longer than the $\mathrm{C}-\mathrm{O}$ bond distance and the bond angle at the nitrogen atom about $150^{\circ}$. In order to obtain agreement for the outer regions of the RD curves various "rigid" models and models based on rotating NCO groups were tried. "Non-bonding" repulsions were considered for the postulations of the "rigid" models and of the various probability functions for assumed internal, hindered rotation of the NCO groups about the $\mathrm{Si}-\mathrm{N}$ bonds. Best agreement was obtained however, when free rotation was assumed. The $u$ values of the distances which are depending on the angle of rotation, were assumed independent of this angle and were chosen equal to $0.10 \AA$ $(\mathrm{N}-\mathrm{C}$ and $\mathrm{N}-\mathrm{O})$ and $0.15 \AA(\mathrm{C}-\mathrm{O}, \mathrm{C}-\mathrm{C}$, and $\mathrm{O}-\mathrm{O}$ ). The attempts of improving these $u$ values in the least-squares refinement were unsuccessful. This has not yet been studied further. The structural parameters obtained from the least-squares refinement are listed in Table 1. The calculated curves are based on these values (Figs. 1 and 2). For comparison, the RD curve based on one of the "rigid" models, the one of symmetry $D_{2 d}$ and the eclipsed configuration, is also drawn in Fig. 2. The RD curve based on the model of the same point group but of the staggered configuration is even more unfavourable.

Discussion. The N-O distance for the NCO group is obtained $0.008 \AA$ shorter than the sum of the $N-C$ and $C-O$ bond distances. This may be assumed due to "shrinkage effects". The values of the bond distances and the bond angle at the 